\title{
THE DEMAND AND SUPPLY OF MONEY UNDER HIGH INFLATION: BRAZIL 1974-1994*
}

\author{
Octávio A. F. Tourinho**
}

\begin{abstract}
A specification for the demand for money in economies where inflation is high and stochastic is presented. It uses a generalized functional form and includes the variance of the inflation rate as an explanatory variable, and is estimated for Brazil in the period 1974-1994 under the assumption that the monetary policy is passive and that expectations are adaptive. The supply of money is then specified as a generalization to a stochastic environment of the rule proposed by Cagan (1956). The money demand and supply equations are then estimated simultaneously, under rational expectations, by using the Johansen (1991) VEC procedure and interpreting the two cointegrating vectors which arise as the supply and demand equations. The restrictions suggested by the hypothesized theoretical models for the money market equilibrium in high inflation processes are tested and accepted for this data.
\end{abstract}

\section{Resumo}

Este artigo apresenta inicialmente uma especificaçāo da demanda por moeda em economias onde a inflaçāo é elevada e estocástica. Ela usa uma forma funcional generalizada e inclui a variância da taxa de inflação como uma variável explicativa, e é estimada para o Brasil para o período 1974-1994 sob a hipótese de que a política monetária é passiva e de que as expectativas sāo adaptativas. A oferta de moeda é entāo especificada como uma generalizaçāo ao ambiente estocástico da regra proposta por Cagan (1956). A demanda e oferta de moeda são entāo estimadas simultaneamente, sob expectativas racionais, usando o procedimento VEC de Johansen (1991), e interpretando os dois vetores de cointegração que sāo obtidos como representando as equaçōes de oferta e demanda. As restriçōes sugeridas pelos modelos teóricos sugeridos para representar o equilíbrio no mercado de moeda sob processos de inflaçāo elevada sāo testados e aceitas para estes dados.

\footnotetext{
* This paper was produced with the financial support of the Pronex program "Crescimento, Elutuaçōes e Políticas Públicas" of the Brazilian Ministry of Science and Technology. I thank the comments of two anonymous referees of this journal.

** Instituto de Pesquisa Econômica Aplicada, IPEA and Universidade do Estado do Rio de Janeiro, UERJ.
}

\begin{tabular}{llll}
\hline R. de Econometria & Rio de Janeiro & v. 17, $\mathrm{n}^{\mathrm{O}} \quad 2$ 2, pp. 87-118 & Novembro 1997 \\
\hline
\end{tabular} 
The Demand and Supply of Money under High Inflation: Brazil 1974-1994

KSey words: Oferta e demanda por moeda, hiperinflaçāo.

JEL Code: E41, E52, E31 e E63.

\section{Introduction.}

The behavior of the monetary variables under extreme inflation is still a topic of ongoing research in economics for the same reason claimed by Cagan (1956) to justify the study of hyperinflations: they provide a unique opportunity to analyze monetary phenomena. ${ }^{1}$ In those processes the astronomical increases in prices and money dwarf changes in income and other real variables, making it possible to study the relation between monetary variables in almost complete isolation of the rest of the economy. Although in high inflation processes a similar situation occurs, as the large rates of change in nominal variables emphasize the relationship between money and prices, changes in the real variables cannot be disregarded. ${ }^{2}$ These cases provide, however, the opportunity for studying money demand and supply in greater detail than that afforded by the analysis of hyperinflations because their occurrence is more common and they last longer, which implies that they constitute a larger and more complete database on which empirical analysis of monetary phenomena can be performed.

This paper addresses the specification and estimation of the demand and supply of money under high inflation, and proposes a

\footnotetext{
${ }^{1}$ Recent examples of this are the analysis of inflationary episodes in several countries found in Dornbusch and Fischer (1986), Bruno et al (1988), and Dornbusch, Sturzenegger and Wolf (1990), and the continuing research on the hyperinflations.

${ }^{2}$ High inflation can be characterized as an intermediary stage in the process towards extreme inflation. It can be recalled that Cagan (1956 p.25) has defined hyperinflation as a process which generates continuously compounded rates of price increase in excess of $50 \%$ per month, while Dornbusch, Sturzenegger and Wolf (1990 p.2) defined extreme inflation as rates above $15 \%$ or $20 \%$ per month. Dornbusch (1992 p.17) points out that countries experiencing inflation rates of $10 \%$ to $15 \%$ per month for any length of time are moving towards hyperinflation.
} 
model which can be regarded, in some respects, as an extension of the Cagan model. It is shown that treatment of high inflation using Cagan's approach to the study of hyperinflations requires some elaboration with respect to the functional form of the demand for money and the effects of the variability of inflation, the inclusion of the real variables in the analysis, and the joint estimation of money demand and supply.

Although here I report only the results of the model for the Brazilian high inflation of the last two decades, I believe that it has wider applicability, since its features were not obtained in an ad-hoc manner to fit that data, but are derived from theoretical and empirical considerations of a general nature regarding the demand and supply of money under high inflation.

The paper has 3 more sections. The next one summarizes the model of money demand derived in Tourinho (1995), where the functional form of the equation and the uncertainty in the inflation rate play a crucial role. It also discusses the empirical specification of a money demand equation which incorporates those characteristics and shows its coefficients estimated by traditional econometric methods under adaptive expectations for Brazilian data of the period 19741994. In Section 3 the money supply rule motif proposed by Cagan (1956) is generalized to a stochastic inflation environment and the money demand and supply equations are estimated under rational expectations, with data set of Section 2, using Johansen's error correction form of the vector autoregression specification. This allows the identification of both equations, and the acceptance of the restrictions derived earlier from the theoretical models for the demand and supply of money. Section 4 summarizes the conclusions of the paper.

\section{The Demand for Real Balances.}

In analyzing the demand for money in high inflation processes, the effect of changes in the variance of inflation, in addition to 
changes in its level, and have to be considered. Agents decide on their desired money balances taking into account that holding money entails a negative real return equal to the inflation rate, and will economize on them up to the point when the benefits of using money as a transactions medium outweigh that cost. This benefit will induce agents to retain money even at rates of inflation at which casual analysis could lead one to expect a total flight from it, as for example, in hyperinflations. A model incorporating these aspects has been proposed in Tourinho (1995) and estimated for a sample ending in 1992. Here that sample is extended to the end of the Brazilian high inflation process, in June of 1994.

Assume prices of the only consumption good follows an Itô diffusion process given by equation (1), where is the increment of the Wiener stochastic process ${ }^{3} z$, and where the parameters $\pi$ and $\sigma$ are known to the agent and are fixed

$$
\frac{d P}{P}=(\pi d t+\sigma d z)
$$

Money has a null nominal return and, since the devaluation of real balances depends on the change of prices, its price $\left(q_{m}=1 / P\right)$ is stochastic. Its real return can be calculated by Itô's lemma, yielding equation (2)

$$
\frac{d q_{m}}{q_{m}}=\left(-\pi+\sigma^{2}\right) d t-\sigma d z
$$

However, it is assumed that money has a convenience yield, since it allows the agent to economize on the cost of the transactions required to implement his optimal consumption and portfolio plans. No attempt is made here to derive this feature of money from more

${ }^{3}$ See, for example, Merton (1971) or Fischer (1975) for an introduction to the use of the methods of dynamic programming with Itô processes in portfolio selection problems. 
basic considerations, but it is clear that if this yield did not exist money would be a dominated security in this economy, and would not be held in positive amounts in the agent's portfolio. ${ }^{4}$ The usefulness of money is modeled here by introducing in the flow budget balancing equation of the representative agent an expenditure which reflects the cost of holding a fraction of his wealth as indexed bonds. Multiplied by the marginal utility of wealth, this cost can be thought of as the convenience yield of money foregone by the agent.

This cost per unit time is assumed to be a decreasing function of the proportion of the agent's wealth which is allocated to money, to be null when all of his wealth is completely liquid, and to be infinitely high when the fraction of real money balances in his portfolio approaches zero. It is assumed here that it can be adequately approximated by the negative of a logarithmic function where the scale factor is $k>0$. Larger values of $k$ are associated with greater usefulness of money in facilitating transactions, relative to index bonds, and correspond to a larger convenience yield of money.

The approximate solution of the portfolio choice problem under uncertainty when inflation is high yields equation (3), which has the expected signs for the partial derivatives: positive for the variance of inflation and for the convenience yield of money, and negative for inflation and interest rates. It is also interesting to note that if the scale factor of convenience yield of money function $(k)$ is reduced by, for example, the creation of new indexed assets, or by the increase of the liquidity of the existing assets, money demand is reduced in the same proportion

$$
\frac{M}{P}=\frac{k}{\pi-\sigma^{2}+r}
$$

\footnotetext{
${ }^{4}$ An example of a model where the demand for money depends on expected cost per unit time of meeting the required transactions, which in turn is a function of the variability of the inflation rate is Barro (1970) (see his equation (54)).
} 
The functional form of (3) is quite different, especially in terms of implications, from the log linear form employed by Cagan. ${ }^{5}$ This issue can be addressed using as the dependent variable the BoxCox transformation ${ }^{6}$ of the normalized real money balances, denoted $\Phi(z, \lambda)$, while maintaining the linear specification for the independent variables. The use of the Box-Cox transform of the money balances and of all the explanatory variables in estimating money demand equations has been proposed by Zarembka (1968), and applied to model money demand in the USA from 1870 to 1963. K.J. White (1972) and J. Spitzer (1976) have also employed this generalized functional form to estimate money demand. ${ }^{7}$

Now, suppose that the Box-Cox transformed dependent variable is written as a linear function of the expected inflation rate, as in equation (4). It is easy to see that this flexible functional form is capable of representing both the reciprocal and the log-linear transformations, by taking $\lambda=-1$ and $\lambda=0$ respectively. Once the stochastic version of (4) is estimated, these two hypothesis regarding the functional form can be tested by examining the confidence intervals for $\lambda$, as long as $k$ is constant

$$
\Phi(M / P, \lambda)=\gamma+\alpha \cdot\left(\pi-\sigma^{2}+r\right) .
$$

The conditions shown in inequalities (5) place restrictions on $\lambda$, $\gamma$ and $\alpha$ which insure that the money demand equation (4) will have

${ }^{5}$ The functional form of equation (3) is different from the exponential form obtained by Barro (1970).

${ }^{6} \Phi(z, \lambda)=\left\{\begin{array}{ll}\frac{z^{\lambda}-1}{\lambda} & \lambda \neq 0 \\ \log (z) & \lambda=0\end{array}\right\} \quad$ and $\quad \lim _{\lambda \rightarrow 0} \Phi(z, \lambda)=\log (z)$, see Box \& Cox (1964). The advantage of this transformation over the power transformation $z^{\lambda}$ is that it is continuous at $\lambda=0$.

7 The same approach proposed by Zarembka has been used by Prado (1978) to estimate the demand for money in Brazil before 1970, a period of low inflation rates, obtaining what appears to be very weak discrimination between the different functional forms. 
the desired behavior as $\pi$ is varied, as discussed in Tourinho (1995)

$$
\alpha<0, \quad \lambda \leq 0 \text { and } 0<\gamma<-1 / \lambda \text {. }
$$

If $\alpha$ and $\gamma$ are kept constant while $\lambda$ is varied, money balances calculated from the equation with the Box-Cox transformation for $\lambda<0$ will be larger than those calculated from the equation with the logarithmic transformation $(\lambda=0)$. Therefore, the use of the functional form proposed here has the potential to remedy the difficulty encountered by Cagan in explaining the demand for real money balances near the end of the hyperinflation with the log-linear model. In fact, larger absolute values of $\lambda$ correspond to larger money balances, and therefore the largest balances are obtained for the reciprocal function $(\lambda=-1)$.

The elasticity of money balances with respect to inflation $(\varphi)$, at high rates of inflation, depends crucially on the value of $\lambda$. For $\lambda=0$ (the log-linear specification) it increases (in absolute value) without bound as inflation increases, while in the other cases $(\lambda<0)$ it converges to a finite value, as shown ${ }^{8}$ by equation (6)

$$
\lim _{\pi \rightarrow \infty} \varphi=\frac{1}{\lambda} \text {. }
$$

The Box-Cox functional form may also be instrumental in resolving yet another puzzle of the Cagan article: the economies analyzed by him seemed to inflate at a higher rate than the constant rate that would maximize the inflation tax. Since the Box-Cox transformation with $\lambda<0$ will produce a demand for money balances which is larger than the one found in the case of the log transformation $(\lambda=0)$, it will also produce higher optimal rates for inflation tax maximization. It is easy to see that the inflation tax maximizing

\footnotetext{
${ }^{8}$ Equation (6) is obtained by applying L'Hôspital rule to the equation for the elasticity.
} 
rate is an increasing function of the absolute value of $\lambda$. This allows us to further restrict the acceptable values for the Box-Cox shape parameter, since for that rate to be positive it must be required that $\lambda \geq-1$. Aggregating this to (5), we obtain inequality (7), which can be tested to verify if the adopted functional form is a satisfactory representation for money demand

$$
-1 \leq \lambda \leq 0
$$

\subsection{Empirical specification under adaptive expectations.}

This section discusses the regression equation for the demand for money under adaptive expectations, which is estimated in isolation and by single equation techniques, thus begging the questions of identification and simultaneous-equations bias, to which we turn in the next section.

It is assumed that desired and actual cash balances are equal. As a consequence, the reasoning provided by the partial adjustment model to justify the use of the lagged dependent variable as an explanatory variable does not apply. The past behavior of the variables influences the equation for the current period only through the adaptive expectations mechanism operating in the independent variables, as described below.

Letting $C_{t}$ denote the actual instantaneous logarithmic rate of change in prices at time $t$, i.e. it is the discrete sample of the continuous process $d \log P$, denote the expected logarithmic inflation rate at the same point in time $e^{9}$ by $E_{t}$, as shown in equation (8). The

${ }^{9}$ Although the model was specified in continuos time, it is estimated here from a data series which is obtained from a sampling of the continuous processes at discrete intervals (one month). To emphasize this, the new notation is introduced. Hansen and Sargent (1983) have explored the possibility that this aggregation over time could impart significant bias in the estimation of Cagan's model, and concluded that for values of $\beta$ smaller than 1 , in the range of values obtained for the hyperinflations he studied, there is at most a very small asymptotic bias to Cagan's estimate of $\beta$. 
adaptive expectation hypotheses implies that $E_{t}$ can be calculated approximately by a weighted average of past $C_{t}$, with weights that decline exponentially at the rate $\beta_{\theta}$, which measures the speed of adjustment of inflation expectations.

Here I extend the model with adaptive expectations to allow it to deal more accurately with the uncertainty produced by the variability of inflation, by including an estimate of the expected variance of the inflation rate $\left(V_{t}\right)$ in the equation for the demand for money. ${ }^{10} \mathrm{It}$ is further assumed that these expectations are based on the actual past errors, and are also adaptive, with parameter ${ }^{11}\left(\beta_{\nu}\right)$. This is reflected by the third term in the right hand side of equation (8)

$$
\begin{aligned}
\Phi\left(M_{t} / P_{t}, \lambda\right) & =\Gamma+\alpha_{c} E_{t}\left(\beta_{e}\right)+\alpha_{\nu} V_{t}\left(\beta_{e}, \beta_{\nu}\right)+\alpha_{r} R_{t}+ \\
& +\alpha_{y} Y_{t}\left(\beta_{y}\right)+\alpha_{s} S_{t}+\varepsilon_{t}
\end{aligned}
$$

It is important to note that $E_{t}$ is an estimate of the expected value of the drift of the stochastic process for $\log (P)$, which is equal to $\pi-\sigma^{2} / 2$, as can easily be seen by applying Itô's lemma to the Wiener process of equation (1). Therefore, the estimate of $\pi$, which is the term that appears in the demand equation (3), can be obtained by adding to $E_{t}$ one-half of the estimate of the variance $\left(V_{t} / 2\right)$. The estimate of $\sigma^{2}$ can be obtained from the quadratic difference of the process for the logarithm of prices $\left(V_{t}\right)$, because its variance is equal to that of the incremental price process.

${ }^{10}$ On using the variance of the inflation rate in the equation, however, it is useful to be aware of a stylized fact noted by Barro (1970): that the variance of inflation generally depends on the intensity of inflation.

${ }^{11}$ The expectations parameter for the level and the variance of the infiation rate may be different, but in the empirical applications of the model developed here it was assumed that they are equal since there does not seem to exist a compelling reason to expect those two parameters to be significantly different in those cases. This simplifying assumption increases the stability of the non-linear routine used to fit the model, and does not bias the estimation. 
Since the restrictions obtained from equation (3) refer to the coefficients of $\pi$ and $\sigma^{2}$, it is necessary to derive their implications for the coefficients of equation (8). If the coefficients of $C_{t}$ and $V_{t}$ are equal to $\alpha_{c}$ and $\alpha_{\nu}$, then, by the argument of the last paragraph, the expectation of the linear combination $\alpha_{c} C_{t}+\alpha_{\nu} V_{t}$ will be ${ }^{12}$ equal to $\alpha_{c}\left(\pi-\sigma^{2} / 2\right)+\alpha_{\nu} \sigma^{2}$, which reduces to $\alpha_{c} \pi+\left(-\alpha_{c} / 2+\alpha_{\nu}\right) \sigma^{2}$. The hypothesis that $\alpha_{\pi}=-\alpha_{\sigma^{2}}$ in (3) then implies that $\alpha_{\nu}=-\alpha_{c} / 2$, as indicated in (9).

Therefore, the equation for the demand for real balances derived from the theoretical model of section 2.1 implies the restrictions on the coefficients of equation (8) which are summarized in equations (9) and (10)

$$
\begin{aligned}
& \alpha_{c}=\alpha_{r}=-2 \alpha_{\nu}=-1 / k \\
& \lambda=-1 .
\end{aligned}
$$

Expected income and "the" interest rate are also included in equation (8) to capture the real sector effects, which are important in high inflation because it is likely to last for several years, invalidating the usual assumption made in the study of hyperinflation that they can be neglected. Expectations with respect to income $\left(Y_{t}\right)$ are also adaptive, with parameter $\beta_{y}$, on the basis of an index of actual production. The actual interest rate $\left(R_{t}\right)$ is included, under the assumption that it follows a martingale. Following the indication of equation (3), the real interest rate is used, which has the empirical advantage of avoiding the collinearity of the nominal interest rates with the rate of inflation. Finally, a variable to account for seasonal factors $\left(S_{t}\right)$ is also included.

The maximum likelihood estimate of the non-linear system composed of the definitions of $E, V$ and $Y$ and of equation (8) is obtained by using an extension of the method proposed by Zarembka (1968). After the appropriate normalization of $M / P$, the non-linear

\footnotetext{
12 For this to follow under the hypothesis of this section, it is necessary to assume that adaptive expectations are also rational.
} 
least squares regression of $\Phi(z, \lambda)$ on the vector of the explanatory variables is run for each of several possible values ${ }^{13}$ of $\lambda$. In this process maximum likelihood estimates of the expectations parameters $\beta_{e}$ and $\beta_{y}$, and of the non-observable variables $E, V, Y$ are also obtained. Finally, the value of $\lambda$ that yields the minimum residual sum of squares is chosen as the estimate of the shape parameter. The confidence interval for $\lambda$ can be obtained from the likelihood ratio test, if the sample is large enough.

Since the Box-Cox transform produces large negative values for $\Phi(z, \lambda)$ when the inflation rate in very high, and in that case the measurement error is also likely to be large, the error variance was assumed to be proportional to the inflation rate $\left(\sigma_{\varepsilon}=\sigma E\right)$. Correction for this assumed heteroscedasticity of the residuals is done in the usual way. Also, since there may exist serial correlation in the residuals of the optimal equation, a Cochrane-Orcutt correction is applied to it, if necessary. These two adjustments allow the use of the estimated standard errors of the coefficients with reasonable confidence if the values of the other statistics for the equation are satisfactory.

\subsection{Money demand in Brazil 1974-1994.}

The modeling strategy advanced here was applied to Brazilian data for the period 1974:2 to 1994:6 with monthly data. Two different concepts of money were used: the monetary base (M0) and M1, but only the coefficients estimated for the narrower concept are shown here, since the results are similar for the two aggregates, and the conclusions of the empirical analysis do not depend much on which concept is preferred. It was also necessary to include a dummy variable for the periods corresponding to the December months because of the anomalous behavior of real balances near the end of the calendar year.

\footnotetext{
${ }^{13}$ The values of $\lambda$ are chosen to span the relevant range, which is given in inequalities (3).
} 
The coefficients for three equations, which differ on the sample period, are displayed in Table 1: equation B1 refers to the complete sample, while B2 and B3 refer respectively to the sub-periods before and after 1985:1, which were estimated to evaluate the structural stability of the model, and to try to identify behavioral shifts that may occur in the route to hyperinflation. The estimated values for $\lambda$ in equations B1, B2 and B3 are respectively $-1.0,-0.8$, and -0.9 , so that condition (7), which summarizes the theoretical restrictions on the value of the Box-Cox shape parameter, is respected by the point estimate of $\lambda$ in all equations.

The value of $\lambda$ in all equations indicates that the shape of the money demand curve is very similar to that of the reciprocal function when inflation is high. Therefore, it appears that the hypothesis made in Tourinho (1995) regarding the nature of the convenience yield of money, which led to equation (3), is satisfactory. The $95 \%$ confidence intervals for $\lambda$ also show that the hypothesis that the true shape of the money demand schedule is the reciprocal function cannot be rejected, and this remains true even at more stringent confidence levels. However, Cagan's log-linear form $(\lambda=0)$ can be rejected in all three equations.

The reasoning above is strictly correct only if $k$, the parameter of the convenience yield function, has the same (constant) value in the two sub-periods. To assess if that is a reasonable hypothesis here, recall first that the coefficient of the inflation rate is equal to $-1 / k$ if the true functional form is the reciprocal function (equation (3)), and note that the intersection of the $95 \%$ confidence intervals for that parameter in the three equations is approximately $(-1.29$, $-1.37)$, which is non-empty. The hypothesis that $k$ is constant cannot be rejected, even as the average monthly inflation rate goes from $5.1 \%$ to $16.5 \%$, in the samples of equations B2 and B3 respectively. ${ }^{14}$

\footnotetext{
${ }^{14}$ The low significance of the variance of inflation in equation B2 is not inconsistent with the development in section 2 because equation (3), which shows that it must be a significant variable in the demand for real money balances, was derived for high rates of inflation.
} 
Table 1

Estimates of the Demand for Real Money Base in Brazil (1974-1994)

\begin{tabular}{|c|c|c|c|}
\hline Equation code number & $\mathrm{B} 1$ & $\mathrm{~B} 2$ & B3 \\
\hline Initial date & $1974: 3$ & $1974: 2$ & $1985: 3$ \\
\hline Final date & 1994:6 & 1985:1 & 1994:6 \\
\hline Observations & 244 & 132 & 112 \\
\hline Degrees of freedom & 236 & 124 & 104 \\
\hline$R^{2}$ & 0.9842 & 0.9829 & 0.9729 \\
\hline Sum of Squared Residuals & 19.504 & 4.813 & 5.750 \\
\hline Standard Error of the Estimate & 0.287 & 0.197 & 0.234 \\
\hline Durbin-Watson & 2.343 & 2.117 & 2.238 \\
\hline $\begin{array}{l}\text { Shape parameter of the Box-Cox } \\
\text { functional form }-\lambda\end{array}$ & $\begin{array}{c}1.0 \\
(-1.04,-0.98)\end{array}$ & $\begin{array}{c}-0.8 \\
(-1.09,-0.53)\end{array}$ & $\begin{array}{c}-0.9 \\
(-1.16,-0.72)\end{array}$ \\
\hline $\begin{array}{l}\text { Parameter of adaptive expectations for } \\
\text { the level and variance of inflation }-\beta_{e}\end{array}$ & $\begin{array}{c}0.13 \\
(0.119,0.144)\end{array}$ & $\begin{array}{c}0.09 \\
(0.067,0.122)\end{array}$ & $\begin{array}{c}0.15 \\
(0.132,0.172)\end{array}$ \\
\hline $\begin{array}{l}\text { Parameter of adaptive expectations for } \\
\text { expected income }-\beta_{y}\end{array}$ & $\begin{array}{c}0.06 \\
(0.045,0.080)\end{array}$ & $\begin{array}{c}0.06 \\
\text { (fixed) }\end{array}$ & $\begin{array}{c}0.06 \\
\text { (fixed) }\end{array}$ \\
\hline Intercept $-\Gamma$ & $\begin{array}{c}0.308 \\
(0.159)\end{array}$ & $\begin{array}{c}0.906 \\
(0.212)\end{array}$ & $\begin{array}{c}0.245 \\
(0.609)\end{array}$ \\
\hline $\begin{array}{l}\text { Coefficient of the expected geometric } \\
\text { rate of inflation }-E\end{array}$ & $\begin{array}{l}-1.438 \\
(0.074)\end{array}$ & $\begin{array}{l}-1.154 \\
(0.108)\end{array}$ & $\begin{array}{l}-1.400 \\
(0.085)\end{array}$ \\
\hline $\begin{array}{l}\text { Coefficient of the expected variance of } \\
\text { the rate of inflation - } V\end{array}$ & $\begin{array}{c}0.941 \\
(0.102)\end{array}$ & $\begin{array}{c}0.140 \\
(0.392)\end{array}$ & $\begin{array}{c}1.620 \\
(0.169)\end{array}$ \\
\hline $\begin{array}{l}\text { Coefficient of the normalized short } \\
\text { term interest rate }-R\end{array}$ & $\begin{array}{l}-0.113 \\
(0.028)\end{array}$ & $\begin{array}{l}-0.100 \\
(0.020)\end{array}$ & $\begin{array}{l}-0.095 \\
(0.045)\end{array}$ \\
\hline $\begin{array}{l}\text { Coefficient of the normalized expected } \\
\text { real income index }-Y\end{array}$ & $\begin{array}{c}0.616 \\
(0.209)\end{array}$ & $\begin{array}{c}1.935 \\
(0.286)\end{array}$ & $\begin{array}{c}0.697 \\
(0.679)\end{array}$ \\
\hline $\begin{array}{l}\text { Coefficient of the dummy variable for } \\
\text { December months }-S * E\end{array}$ & $\begin{array}{c}0.222 \\
(0.018)\end{array}$ & $\begin{array}{c}0.084 \\
(0.011)\end{array}$ & $\begin{array}{c}0.256 \\
(0.028)\end{array}$ \\
\hline $\begin{array}{l}\text { Correlation coefficient of the } \\
\text { residuals - } r \text { ho }\end{array}$ & $\begin{array}{c}0.806 \\
(0.040)\end{array}$ & $\begin{array}{c}0.834 \\
(0.052)\end{array}$ & $\begin{array}{c}0.685 \\
(0.072)\end{array}$ \\
\hline
\end{tabular}

The values in parentheses below the estimates of $\Gamma$, and $\rho$ of the coefficients of $\pi, \sigma^{2}, R, Y, t$ and $S * E$ are standard errors. All coefficients are significant at the $5 \%$ level, with exception of the one marked with an *. The pair of values below the estimates of $\lambda, \beta_{i}$ and $\beta_{y}$ is their $95 \%$ confidence interval. The estimates for all the parameters, their confidence intervals and standard errors, are conditional on the value of $\lambda$ shown for each equation. The equations were estimated with corrections for heteroscedasticity and serial correlation of the residuals. The statistics for the fit of the equation in the upper part of the table refer to the corrected equation. 
The estimated value of the parameter for the formation of expectations for the level and the variance of inflation $\left(\beta_{e}\right)$ in equation B1 is equal to 0.13 , implying that expected values lag observed values by an average of 7.7 months. This is the mean value of that lag for the whole sample, since there is evidence that it is larger when inflation is relatively low, and decreases as it accelerates, an effect whose existence was first conjectured, but not proved, by Cagan (1956). Here it can clearly be shown to have happened in Brazil, by noting that the estimate of the expectations parameter for the initial phase of the high inflation process (equation B2) is equal to 0.09 , while for the extreme inflation phase it is equal to 0.15 (equation B3). The increase of $\beta_{e}$ reflects the reduction of the average lag in expectations formation, from 11 months to 6.6 months, which occurs in response to the increase in the average level of inflation associated with the second sub-period. The confidence intervals for $\beta_{e}$ are reasonably tight around the respective point estimates, allowing great assurance in drawing the conclusion that the average expectations lag shortens substantially as inflation increases: the upper limit for that confidence interval in equation B2 is 0.12 , while the lower limit in equation $\mathrm{B} 3$ is 0.13

The estimate of the expectations parameter for expected income $\left(\beta_{y}\right)$ in equation $\mathrm{B} 1$ is equal to 0.06 , implying an average lag with respect to the actual income index of 17 months. This lag is more than double that of inflation expectations for the same period, and is consistent with the idea that expected income ought to respond rather slowly to shocks. Equations B2 and B3 were estimated with that parameter fixed, since their sample periods are not long enough (given the observed variation in the income index) to allow it to be estimated reliably.

The other important empirical implication of the model is equation (9): the coefficients of the level and of the variance of the inflation rate have to be equal to $-1 / k$ and $1 / 2 k$ respectively. Although 
the coefficients have the expected signs, the theoretical hypothesis derived for the demand for real balances in rejected in all equations.

The relative values of the coefficient of the variance of inflation in equations B2 and B3 is what would be expected: when inflation is relatively low agents are unconcerned with its variability, leading to an insignificant coefficient, while in the extreme inflation situation they become acutely aware of the inflationary risk (especially due to the several shocks of that period), leading to a larger coefficient.

Another implication of the model is that the coefficient of the real interest rate should also be equal to $-1 / k$, the same coefficient of the inflation rate. Although the sign of the estimated coefficients for $R$ is right in all equations, its value is about one tenth of what was expected from equation (8). One can conjecture that the reason for this failure to satisfy the theoretical restriction is that the estimated value of this coefficient may be subject to a problem of simultaneous equations bias, since the real interest rate is the channel through which the interaction with the money supply equation would operate. This problem is addressed in the next section.

The equality of the coefficients of the linear part of the specification in the two sub-periods can be evaluated by performing a Chow test on the equations estimated with the values of shape and expectations parameters ( $\lambda$ and $\beta$ 's) constrained to equal those estimated for the whole period in equation B1. That conditional test rejects, at the $5 \%$ significance level, the hypothesis that those coefficients are equal. However, the same test at the $1 \%$ significance level is unable to reject the stability hypothesis.

\section{Money Demand and Supply.}

In this section a money supply rule is introduced in the model to solve the identification problem pointed out in the last section. The resulting equation system is estimated by using the error correction form of the vector auto regressive model (VEC), in a fashion 
which innovates with respect to the existing literature. ${ }^{15}$ This is so because in the application of cointegration techniques to the estimation of the money demand schedule under high inflation by Montiel (1989), Engsted (1991 and 1993), and Phylaktis and Taylor (1992), the money supply process is not modeled. For Brazilian data, Rossi (1994) applies the methodology proposed by Phylaktis and Taylor (1992) and by Engsted (1993) to test cointegration of money and prices in a log-linear equation, but also does not discuss the supply of money, nor includes in the analysis the other variables used in the last section.

\subsection{The money supply model.}

Here the money supply rule first suggested by Cagan (1956) is used to specify the other equation of the money market equilibrium. For simplicity, assume that the deficit is equal to the sum of a roughly fixed primary deficit $^{16}(G)$ and the financial component of the deficit, which is the real interest cost of the public debt. Given an initial level of government indebtedness $(D)$, if all further deficits are financed by money creation, the total deficit will be a linear function of the real interest rate, as indicated in the left hand side of equation (11). Suppose further that the government plans to finance the total deficit with the expected inflation tax, which is equal to the product of the demand for real balances and the expected rate of decrease in

\footnotetext{
${ }^{15}$ The use of an alternative approach, proposed by Sargent (1977) for eliminating the potential simultaneous-equations asymptotic bias of Cagan's model, is not very attractive because it yielded "loose" estimates of the relevant parameters when it was applied to the hyperinflations studied by Cagan (1956).

${ }^{16}$ The primary deficit is defined as the difference between the non-financial expenditures and the tax revenue.
} 
their real value. ${ }^{17}$ As pointed out earlier, under the assumption that inflation follows the stochastic process in (1) that rate is equal to $\left(\pi-\sigma^{2}\right)$, and the money supply rule can be represented by equation $(11)$ :

$$
G+r D=\frac{M}{P} \cdot\left(\pi-\sigma^{2}\right) .
$$

Using the Box-Cox transform with parameter $\lambda=-1$, equation (11) can be written as equation (12), which can be used to interpret the results of the VEC estimation which will be discussed in the next section.

$$
\Phi(M / P,-1)=\frac{-1}{G+r D}\left(\pi-\sigma^{2}\right) .
$$

Equation (13) can then be obtained by taking the Taylor series expansion with respect to $r$ of the fraction in the right hand side of (12), in the neighborhood of zero. For future reference, the money demand equation of section 2.1 (equation (3)) is rearranged and displayed below as equation (14)

$$
\begin{aligned}
& \Phi(M / P,-1)=\frac{-1}{G}\left(\pi-\sigma^{2}\right)+\frac{D}{G^{2}}\left(\pi-\sigma^{2}\right) r \\
& \Phi(M / P,-1)=\frac{-1}{k}\left(\pi-\sigma^{2}\right)+\frac{-1}{k} r .
\end{aligned}
$$

Equation (13) shows that the money supply rule implies a longrun relation between the reciprocal of real balances and $\pi, \sigma^{2}$ and $r$ which is similar to that of the money demand equation (equation (14)). First, note that in both equations the coefficients $\pi$ and $\sigma^{2}$

17 This hypothesis is slightly different from the one adopted by Sargent and Wallace (1973), that specify instead that the deficit is financed by seignorage alone. The approach here implies a less myopic behavior of the Government which recognizes that inflationary finance will induce accelerating inflation and a reduction of real balances, which is non-interest paying debt. 
are equal in absolute value, but have opposite signs. The economic interpretation, and the value, of these coefficients will however be different in the two equations. It is the reciprocal of the parameter that represents the convenience yield of money in the demand equation, while for money supply it is the reciprocal of the primary deficit. Second, note that the coefficient of the interest rate in the two equations also corresponds to different parameters. In equation (14) it is equal to the coefficient of the expected inflation rate, but in the in the long run relation between the variables which was attributed above to the money supply rule, its value will reflect the average value of the coefficient of $r$ in equation (13). Its sign will be opposite to that of the inflation rate, and in high inflation processes its absolute value is likely to be larger than that of the expected inflation rate.

One can also solve the system (13) and (14), to obtain equation (15) which determines the real interest rate as a function of the inflation rate adjusted for volatility and of the other parameters:

$$
r^{2} D+r\left(\pi-\sigma^{2}\right)(1+D)+\left(\pi-\sigma^{2}\right)(G-k)=0
$$

Before the model is estimated, a term proportional to the income variable $(y)$ is added to both equations because it is a relevant variable for the determination of money demand and supply, as will be argued below, ${ }^{18}$ and when is introduced in this way, keeps the model simple and estimable.

The coefficient of income in the augmented demand equation will capture the effect usually attributed to the transactions demand for money and, by making the current model consistent with the model of section 2, allows comparisons with the estimated coefficients of equation (8).

${ }^{18}$ The income variable was omitted from the model of sections 2.1 and 3.1 to avoid cluttering the algebra. 
In the supply equation the coefficient of the income variable reflects the way in which the Government increases the real money base in response to increases in income. Here we will assume that the supply of real balances is homogenous to the first degree with respect to income at the average of the sample points. ${ }^{19}$ This unitary elasticity would be obtained within the framework suggested above to derive equation (13) if tax revenues and government expenditures are supposed to be proportional to income, implying that the deficit, which is subject to inflationary finance, is also proportional to income. Given the functional form of the augmented supply equation, this can be imposed on the model in an approximate way by requiring that the coefficient of income be equal to one, because the dependent and independent variables are normalized to average one over the sample, as discussed in section 2 .

\subsection{Estimation of the money supply and demand system.}

Equations (13) and (14) augmented by the income variable specify two long-run relations between $\Phi(M / P,-1), \pi, \sigma^{2}, r$ and $y$ which can be estimated as the cointegrating vectors of a vector autoregression (VAR), as discussed below. Here the adaptive expectations hypothesis will be dropped in favor of a rational expectations formulation, taking advantage of the fact that the lagged variables in the

19 There could also exist indirect ways in which income could affect money supply. In a tax system where indirect taxes play the dominant role, such as the Brazilian, increases in income will increase tax revenues and reduce the need use inflationary finance, leading to a negative effect on the Box-Cox transformed money base. There may also be a long run tendency for increases in income to be associated to increases in Government expenditure which, other things held constant, will have to be financed by increases in the money supply. 
VAR can account not only for the types of propagation effects implied by the adaptive expectations, but also for other mechanisms. ${ }^{20}$ The estimation of the model in this section is therefore free from the risk of being biased by the choice of the expectations mechanism.

As in the previous section inflation will be measured by the first difference of the logarithm of prices $\left(C_{t}\right.$ in the notation of the Section 2) and the estimate of $\sigma^{2}$, which is denoted $V_{t}$, will be obtained from the data by moving over it a sliding window of 10 periods of span centered on the date for which the variance is being calculated, ${ }^{21}$ which avoids the need to estimate it adaptively from past errors, as was done in Section 2. However, because of the way in which this variable obtained, it is treated as weakly exogenous and is not included in the autoregressive vector.

The model is estimated in the error correction form (VEC) shown in equation (16), by using the maximum likelihood procedure proposed by Johansen (1988 and 1991). The VEC has been applied to the estimation of the demand for money in Johansen and Juselius (1990) and (1994), but they do not consider the possibility that the money supply rule could be responsible for an additional long-run relation between the variables. This effect, however, is only relevant when the inflation tax is use to finance the public deficit, in high inflation processes, and may not be present in the situation studied

${ }^{20}$ There is not an a priori incompatibility between the expectations hypothesis in this and in section 2, since as Sargent and Wallace (1973) show, adaptive expectations can be rational in the sense of Muth (1961) if expectations regarding the future growth of the money supply are formed on the assumption that the government is financing a roughly fixed rate of real expenditures by money creation. In their empirical analysis they conclude (p. 342): "Our explanation for the feedback from $X$ to $m$ (inflation to money) tends to confirm the wisdom of Cagan's decision to model expectations by extrapolation of lagged rates of inflation. Such method of forming expectations seems to have been rational".

${ }^{21}$ The size of the window was chosen by evaluating the trade-off between stability and responsiveness of the estimated variance. 
in that paper.

$$
\begin{aligned}
\Delta X_{t} & =\sum_{i=1}^{k-1} \Gamma_{i} \cdot \Delta X_{t-i}+\omega \theta^{\prime} X_{t-1}+\mu+\psi S_{t}+\varepsilon_{t} \\
X_{t} & =\left(\Phi\left(M_{t} / P_{t}-1\right), C_{t}, R_{t}, Y_{t}, V_{t}\right) .
\end{aligned}
$$

The variables in the autoregressive vector are the ones shown in definition (17), except for the variance, which is exogenous. Also, in $X_{t}$ the empirical variables have substituted for the theoretical parameters. There are also 11 seasonal dummy variables $\left(S_{t}\right)$, one for each month, and a linear trend for the level of each of the variables. In addition, since the inflation stabilization attempts included, in their initial months, several measures which hindered the functioning of markets (price freezes, for example) impulse dummy variables were also used control for outliers in those periods. ${ }^{22}$ The variables for the following dates turned out to be significant: 1986:2, 1987:6, 1988:12, 1989:1, 1989: 2, 1990:3, 1991:2, 1992:12 and 1993:12. The possibility that those shocks shifted the vector $\mu$ of equation (16) is also taken into account, by including step dummy variables starting at the dates when the graph of the inflation rate reached a valley after those policy shocks: 1986:4, 1987:8, 1989:4 and 1990:2. The number of lags in the VEC was chosen to be equal to 4 by the Akaike information criterion.

The hypothesis that there are two linear combinations of the variables which are stationary, as suggested by the analysis of the last section, is that the rank of the $5 \times 5$ matrix $\omega \theta^{\prime}$ (where $\omega$ and $\theta$ are $5 \times 2$ matrixes of full rank) is equal to 2 . The two column vectors in $\theta$ can then be interpreted as the long run relations of equations

${ }^{22}$ It was not necessary to use these dummy variables for the stabilization plans in the previous section because only the demand for money was of interest, as opposed to the situation here, where all the variables in the vector (including the inflation rate) are modeled. 
(13) and (14). Once the hypothesis that the cointegration rank is equal to 2 is accepted, the long run relations must still be found by estimating them under the hypothesis implied by the analysis of sections 2.1 and 3.1, and their joint acceptance must be tested, by verifying if $\theta$ has the form displayed in equation (18)

$$
\theta^{\prime}=\left[\begin{array}{ccccc}
\Phi(M / P,-1) & C & R & Y & V \\
1 & \theta_{11} & \theta_{11} & -\theta_{41} & -\theta_{11} / 2 \\
1 & \theta_{22} & -\theta_{32} & -1 & -\theta_{22} / 2
\end{array}\right]
$$

where $\theta_{11}, \theta_{41}, \theta_{22}, \theta_{32}$ and $\theta_{42}>0$.

The values of the coefficients in the last column of the matrix in (18) are a consequence of the fact that the hypothesis developed in the theoretical models refer to $\pi$ and $\sigma^{2}$, rather than to the empirical variables used to estimate them in the model, as has already been discussed in section 2.2, in connection with equation (8).

Estimation of the system is possible because the set of restrictions in (18) is generically identifying, ${ }^{23}$ in the sense of Johansen (1995), i.e. that "almost all" cointegrating vectors that satisfy those restrictions are identified. ${ }^{24}$ The Appendix demonstrates that the appropriate rank conditions are satisfied in this case.

The loading vector $\omega$ measures the speed of convergence to the equilibrium when there are shocks in the cointegration relations, and to some extent plays the role, at least with respect to the real money balances, that the adaptive expectations coefficient played in the model of section 2 .

23 I thank an anonymous referee of this journal for calling my attention to the need to investigate the identification issue more thoroughly, and indicating the reference in the text.

24 Note that the homogeneity of the money supply equation with respect to income, which is reflected in the coefficient -1 in (18), is necessary to insure generic identification. In its absence the space spanned by the demand restriction would be contained in the space spanned by the supply restriction, violating the condition for generic identification (see Johansen (1995)). 


\subsection{Empirical results.}

The variables of vector $X_{t}$ (described in equation (17)), were tested for the existence of a unit root using the Augmented DickeyFuller (ADF) and Philips-Perron (PP) tests for the period 1974:1 to 1994:6. Both tests were calculated without a linear trend, and the lag length is selected optimally for the ADF test and is equal to 12 for the PP test. The values of test statistic are shown in Table 2, leading to the acceptance of the hypothesis that the variables are $I(1)$, with the exception of the real interest rate, which is $I(0)$. Since a stationary variable is included in the cointegration relation, the order of cointegration is at least 1 .

Table 2

Test statistics $t(\rho-1)$ for the existence of a unit root:

Augmented Dickey-Fuller (ADF) and Phillips-Perron (PP)

\begin{tabular}{lccccc}
\hline Test & $95 \%$ Value & $M / P$ & $C$ & $R$ & $Y$ \\
\hline ADF & -2.8735 & -1.1314 & -2.8590 & -10.1524 & -2.1472 \\
PP & & -1.2077 & -2.3550 & -10.5852 & -2.0404 \\
\hline
\end{tabular}

Since the hypothesis that $\lambda=-1$ was accepted in the reduced form model of the previous section, the use of the specification of equations (13) and (14) was validated. The model of equation (16) was then estimated with the CATS procedure of Hansen and Juselius (1995) for the period 1974:01 to 1994:06 which, given the effective sample, yields 191 degrees of freedom. Table 3 displays the likelihood and trace test statistics for cointegration order, showing clearly the existence of two cointegrating vectors, in spite of the fact that the critical values shown are not the correct ones because the model includes an exogenous variable $(V)$. 
The Demand and Supply of Money under High Inflation: Brazil 1974-1994

Table 3

Likelihood and Trace Tests of Cointegration Order

\begin{tabular}{ccccccc}
\hline & \multicolumn{2}{c}{ Statistics } & \multicolumn{3}{c}{ Critical values } \\
\hline Eigenvalues & L-max. & Trace & H0:r & p-r & L-max. 90 & Trace 90 \\
\hline 0.3201 & 92.60 & 144.74 & 0 & 4 & 17.15 & 43.84 \\
0.1696 & 44.62 & 52.14 & 1 & 3 & 13.39 & 26.70 \\
0.0254 & 6.18 & 7.53 & 2 & 2 & 10.60 & 13.31 \\
0.0056 & 1.34 & 1.34 & 3 & 1 & 2.71 & 2.71 \\
\hline
\end{tabular}

The multivariate statistics show a trace correlation of 0.757 and the following values for the information criteria: Schwarz $=-15.364$ and Hannan-Quinn $=-17.061$. The autocorrelation of the residuals cannot be eliminated completely for this data by taking differences, probably because of the non-stationarities which are due to the stabilization shocks. The $R^{2}$ for the univariate regressions for the first difference of the components of $X$ are respectively equal to 0.783 , $0.845,0.703,0.709$. Normality of the residuals of those regressions is also rejected, but inspection of their distribution suggests that this may not be a serious problem.

The joint hypothesis on the long-run relations implied by the money demand and supply theoretical models, which are summarized in equation (18), cannot be rejected since the likelihood ratio test yields $\chi^{2}(1)=1.14$, corresponding to a $\mathrm{p}$-value of 0.56 . This shows that the rejection of restrictions (9) in the model of equation (8) may have occurred because the test was done on the reduced form equation, which in fact is not the demand schedule. 
The restricted cointegrating vectors are shown in Table 4. First it should be noted that the effect of the risk-adjusted inflation rate in the two equations is very similar. It is also quite interesting to note that although no restriction is placed on the coefficient of the interest rate in the supply equation, it has the expected sign. Table 4 also shows that the effect of output on money demand is positive, but it is clear that the elasticity of money demand is smaller than one (recall that the hypothesis that the elasticity of supply is unity is accepted by the data).

The coefficients for $R$ in the two equations of Table 4 are of opposite signs, which suggests that a linear combination of them may yield the very small estimated coefficient reported in Table 1. If the stand-alone money demand equation estimated in Section 2 is in fact a reduced form that corresponds approximately to a linear combination of the supply and demand long run relations isolated in this section, then the coefficient of $R$ can be used to obtain the proportion in which those two cointegrating vectors were combined.

Table 4

Cointegrating vectors of restricted model

\begin{tabular}{lccccc}
\hline Vector & $\Phi(M / P,-1)$ & $C$ & $R$ & $Y$ & $V$ \\
\hline Demand & 1.000 & 1.444 & 1.444 & -0.496 & -0.722 \\
Supply & 1.000 & 1.612 & -0.457 & -1.000 & -0.806 \\
\hline
\end{tabular}

Table 5 shows the coefficients for equation (3) reported in Table 1 , and the coefficients of a linear combination of the cointegrating vectors where $30 \%$ of the weight falls on the money demand equation, which yields a coefficient for $R$ which is very similar to the reduced form equation. The reason for looking with priority at the coefficient of the interest rate in computing this weight is that it is the price which equilibrates the money market, as suggested by equation (15). Comparison of the coefficients of the two equations in Table 5 shows 
The Demand and Supply of Money under High Inflation: Brazil 1974-1994

that all of them are quite similar, confirming the conjecture that the anomalies observed in the reduced form of the last section were in fact due to an identification problem.

\section{Table 5}

Comparison of linear combination of cointegrating vectors with the money demand equation (8)

\begin{tabular}{lrrrr}
\hline & $C$ & $R$ & $Y$ & $V$ \\
\hline Linear combination of cointegrating vec tors & & & & \\
$(0.30 *$ demand $+0.70 *$ supply) & -1.562 & -0.113 & 0.849 & 0.781 \\
Money demand equation of Table 1 & -1.438 & -0.113 & 0.616 & 0.941 \\
\hline
\end{tabular}

Table 6 displays the matrix $\omega$ defined in equation (16), which shows the loading of the deviations in the cointegrating relations in the error correction term of the equations for $\Delta X$. They refer to the cointegrating relation for the money demand, which is positive if real balances exceed what is demanded (there is excess supply of money), and to the one for money supply, which is positive if real balances exceed the desired supply (there is excess demand).

\section{Table 6}

Loading of the cointegration relations in the VEC

\begin{tabular}{lcccc}
\hline & $\Delta \Phi(M / P,-1)$ & $\Delta C$ & $\Delta R$ & $\Delta Y$ \\
\hline \multirow{2}{*}{$\omega$-demand } & -0.052 & -0.021 & -0.294 & -0.013 \\
\multirow{2}{*}{$\alpha$-supply } & $(-1.755)$ & $(-0.384)$ & $(-5.987)$ & $(-1.296)$ \\
& -0.102 & -0.162 & 0.251 & -0.011 \\
& $(-4.457)$ & $(-3.906)$ & $(6.604)$ & $(-1.331)$ \\
\hline
\end{tabular}




\section{Conclusion.}

In Section 2 the money demand equation derived in Tourinho (1995) is estimated for a sample extending up to June 1994, which marks the end of the recent Brazilian high inflation period. In that model the reciprocal of the real money balances is a linear function of the level and of the variance of the rate of inflation, the real interest rate and of income. Several testable implications of the theoretical model were derived: the coefficients of the expected level and variance of the inflation rate should have the same absolute value and opposite sign, and the coefficient of the real interest rate should equal that of the expected level of the inflation rate. The functional form is tested by using a generalized functional form of the real money balances (the Box-Cox transform) as the dependent variable. The empirical specification was completed with the introduction of a variable to capture the effects of technological progress, and of a seasonal factor.

To estimate the model a maximum likelihood non-linear regression procedure was used, under the assumption that money supply is passive and that expectations for the inflation rate, its variance, and income are adaptive. The results validate the model proposed, and the hypothesis regarding the functional form and the coefficients are accepted.

In Section 3 the money supply rule is specified as a generalization to a stochastic environment of the rule suggested by Cagan (1956) and formalized by Sargent and Wallace (1973). It yields a money supply function where the reciprocal of the real money balances are a function of the level and the variance of the inflation rate, and of the real interest rate. As with the money demand equation, the coefficients of the expected level and variance of the inflation rate are symmetric, but the coefficient of the interest rate has a different magnitude and opposite sign, relative to that of the inflation rate. 
The money demand and supply equations are then estimated under rational expectations for the same data of Section 2 by using Johansen's error correction form of the vector autoregression specification. The vector is composed of the negative of the reciprocal of real money balances, the level and the variance of the inflation rate, the real interest rate, and income. Seasonal dummies and trends are also used, and the variance of inflation is treated as being weakly exogenous.

The estimated cointegrating relations are identified as the money demand and supply equations, since the restrictions suggested by the theoretical models can be accepted. Comparison of the estimates of the coefficients of the structural system with that of the equation (8) shows that it is consistent with it and corrects the simultaneous equations bias which occurred in the estimation of the interest rate coefficient in the reduced form equation.

In summary, a theoretical specification for the demand and supply for real balances in high inflation processes which extends and generalizes Cagan's celebrated hyperinflation model has been derived and used successfully to estimate the monetary equilibrium in the Brazilian high inflation process of the last 2 decades.

Submetido em Dezembro de 1996. Revisado em Maio de 1998.

\section{References}

Barro, Robert J. 1970. "Inflation, the payments period, and the demand for money." Journal of Political Economy 78:12281263.

Box, G.E.P. \& D.R. Cox. 1964. "An analysis of transformations (with discussion)." Journal of the Royal Statistical Society 26(Series B):211-243.

Bruno, M.; G. Di Tella; R. Dornbusch \& S. Fischer (eds.). 1988. "Stopping High Inflation". Cambridge, Mass: MIT Press. 
Cagan, Phillip. 1956. "The monetary dynamics of hyperinflation." In: M. Friedman (ed.), Studies in the Quantity Theory of Money. Chicago: University of Chicago Press.

Cardoso, E.A. 1983. "A money demand equation for Brazil." Journal of Development Economics 12:183-193.

Darrat, A.F. 1985. "The demand for money in Brazil. Some further results." Journal of Development Economics 18:485-491.

Dornbusch, R. 1992. "Lessons from experiences with high inflation." The World Bank Economic Review 6(1):13-31.

Dornbusch, R. \& S. Fischer. 1986. "Stopping hyperinflations: past and present." Weltwirtschaftliches Archiv 122(1):1-14.

Dornbusch, R.; F. Sturzenegger \& H. Wolf. 1990. "Extreme inflation: dynamics and stabilization." Brookings Papers on Economic Activity 2:1-64.

Engsted, Tom. 1991. "Testing for rational inflationary bubbles: the case of Argentina, Brazil and Israel." Applied Economics 25:667-674.

Engsted, Tom. 1993. "Cointegration and Cagan's model of hyperinflation under rational expectations." Journal of Money, Credit and Banking 25(3):350-360.

Fair, Ray. 1987. "International evidence on the demand for money." Review of Economics and Statistics LXIX:473-480.

Gerlach, S. \& F. Nadal De Simone. 1985. "A money demand equation for Brazil. Comments and additional evidence." Journal of Development Economics 18:493-501.

Goldfeld, S.M. \& D.E. Sichel. 1990. "The demand for money." In: B.M. Friedman and F.H. Hahn (eds.). Handbook of Monetary Economics, Chapter 8. Vol. 1, Elsevier.

Hansen, L.P. \& T.J. Sargent. 1983. "Aggregation over time and the inverse optimal predictor problem for adaptive expectations in 
The Demand and Supply of Money under High Inflation: Brazil 1974-1994

continuous time." International Economic Review 24(1):1-20.

Hansen, H \& K. Juselius. 1995. "CATS in RATS". Cointegration Analysis of Time Series. Estima, Evanston, Ill.

Johansen, S. 1988. "Statistical analysis of cointegrating vectors." Journal of Economic Dynamics and Control 12:231-254.

Johansen, S. 1991. "Estimation and hypothesis testing of cointegration vectors in Gaussian vector autoregressive models." Econometrica 59:1551-1580.

Johansen, S. 1995. "Identifying restrictions of linear equations with applications to simultaneous equations and cointegration." Journal of Econometrics 69(1):111-132.

Johansen, S. \& K. Juselius. 1990. "The full information maximum likelihood procedure for inference on cointegration, with applications to the demand for money." Oxford Bulletin of Economics and Statistics 52:169-210.

Johansen, S. \& K. Juselius. 1994. "Identification of the long-run and the short-run structure: an application to the ISLM model." Journal of Econometrics 63(1):7-36.

Phylaktis, Kate \& D. Blake. 199?. "The Fischer hypotheses: evidence from three high inflation economies." Weltwirtschaftliches Archiv 12:591-599.

Phylaktis, Kate \& M. Taylor. 1992. "The monetary dynamics of sustained high inflation: Taiwan 1945-1949." Southern Economic Journal 58(3):610-622.

Prado, E.F.S. 1978. "Demanda por moeda no Brasil: o problema da forma funcional." Pesquisa e Planejamento Econômico 8(3):781-794.

Rossi, J.W. 1988. "A demanda por moeda no Brasil: o que ocorreu a partir de 1980? Pesquisa e Planejamento Econômico 18(1): $37-54$. 
Rossi, J.W. 1994. "O modelo hiperinflacionário da demanda por moeda de Cagan e o caso do Brasil." Pesquisa e Planejamento Econômico 24(1):73-96.

Sargent, T.J. \& N. Wallace. 1973. "Rational expectations and the dynamics of hyperinflation." International Economic Review 14(2):328-350.

Sargent, T.J. \& N. Wallace. 1975. "Rational expectations, the optimal monetary instrument, and the optimal money supply rule." Journal of Political Economy 83(2):241-254.

Sargent, T.J. 1977. "The demand for money during hyperinflations under rational expectations: I." International Economic Review 18(1):59-82.

Spitzer, J.J. 1976. "The demand for money, the liquidity trap, and functional form." International Economic Review 17(1): 220-227.

Taylor, Mark P. 1991. "The hyperinflation model of money demand revisited." Part 1, Journal of Money, Credit and Banking 23(3):327-351.

Tourinho, O.A.F. 1995. "A demanda por moeda em processos de inflaçāo elevada." Pesquisa e Planejamento Econômico 25(1): $7-68$.

White, K.J. 1972. "Estimation of the liquidity trap with a generalized function form." Econometrica 40(1):193-199.

Zarembka, P. 1968. "Functional form in the demand for money." American Statistical Association Journal 63:502-511.

\section{Appendix.}

\section{Testing the generic identification of the model}

The restrictions derived from in sections 2.1 and 3.1, are summarized in the general form (18) for the cointegrating vectors. This 
appendix uses theorem 3 in Johansen (1995), which is also reported as theorem 1 in Johansen and Juselius (1994), to establish that those restrictions are generically identifying for our model.

To apply the theorem we have to represent the restrictions on the cointegrating vectors $\theta_{i}, i=1,2$, through matrices $R_{i}$ and $H_{i}$, such that $R_{i}^{\prime} \theta_{i}=0$ and $\theta_{i}^{\prime}=\varphi_{i}^{\prime} H_{i}^{\prime}$, where $\varphi_{i}$. are vectors of parameters. These matrixes must satisfy the following conditions: $R_{1}^{\prime} H_{1}=0$ and $R_{2}^{\prime} H_{2}=0$ and are displayed below. Here there are two cointegrating vectors $(r=2)$ and the rank condition reduces to verifying that $\operatorname{rank}\left(R_{1}^{\prime} H_{2}\right)=\operatorname{rank}\left(R_{2}^{\prime} H_{1}\right)=r-1=1$

$$
\begin{aligned}
H_{1}^{\prime} & =\left[\begin{array}{ccccc}
1 & 0 & 0 & 0 & 0 \\
0 & 1 & 1 & 0 & -0.5 \\
0 & 0 & 0 & 1 & 0
\end{array}\right] \quad R_{1}^{\prime}=\left[\begin{array}{ccccc}
0 & 1 & -1 & 0 & 0 \\
0 & 1 & 0 & 0 & 2
\end{array}\right] \\
H_{2}^{\prime} & =\left[\begin{array}{ccccc}
1 & 0 & 0 & -1 & 0 \\
0 & 1 & 0 & 0 & -0.5 \\
0 & 0 & 1 & 0 & 0
\end{array}\right] \quad R_{2}^{\prime}=\left[\begin{array}{lllll}
0 & 1 & 0 & 0 & 2 \\
1 & 0 & 0 & 1 & 0
\end{array}\right] \\
R_{1}^{\prime} H_{2} & =\left[\begin{array}{ccc}
0 & 1 & -1 \\
0 & 0 & 0
\end{array}\right] \Longrightarrow \operatorname{rank}\left(R_{1}^{\prime} H_{2}\right)=1 \\
R_{2}^{\prime} H_{1} & =\left[\begin{array}{lll}
0 & 0 & 0 \\
1 & 0 & 1
\end{array}\right] \Longrightarrow \operatorname{rank}\left(R_{2}^{\prime} H_{1}\right)=1 .
\end{aligned}
$$

Therefore, the proposed restrictions are generically identifying for the model, and "almost all" vectors satisfying them are identified. 